\title{
Advanced Low-Cost Receivers for Parabolic Troughs
}

\begin{tabular}{ll}
\hline NORWICH TECHNOLOGIES & $\begin{array}{c}\text { NORWICH } \\
\text { Technologies }\end{array}$ \\
\hline PROGRAM: & SunShot CSP R\&D 2012 \\
\hline TOPIC: & Advanced Receivers \\
\hline LOCATION: & Norwich, Vermont \\
\hline $\begin{array}{l}\text { AWARD } \\
\text { AMOUNT: }\end{array}$ & Up to \$0.3 million \\
\hline PROJECT TERM: & $2012-2013$ \\
\hline
\end{tabular}

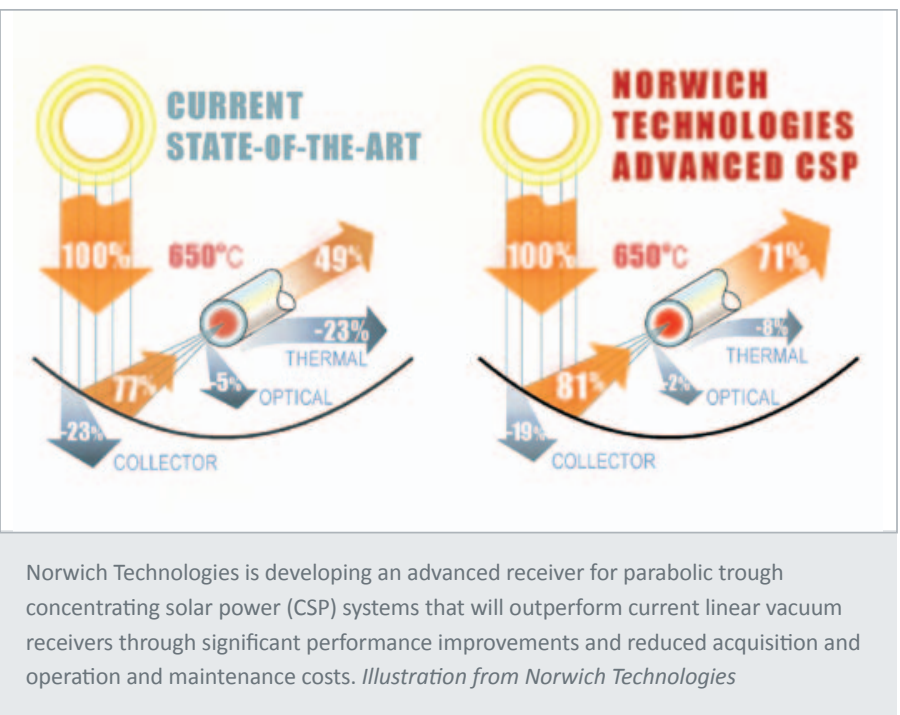

\section{CONTACTS}

Project Leader:

Dr. Joel Stettenheim

stettenheim@norwitech.com
Partnering Organizations:

- Creare, Inc.

- ANSYS, Inc.

\section{MOTIVATION}

Numerous challenges exist with today's state-of-the-art linear vacuum receivers. Some of these drawbacks include expensive and technologically intensive absorption coatings, a $1 \%-5 \%$ annual failure rate for tubes due to vacuum degradation, and prohibitive radiation losses that prevent practical operation at elevated temperatures $\left(>500^{\circ} \mathrm{C}\right)$.

\section{PROJECT DESCRIPTION}

Norwich Technologies is designing a novel receiver that addresses these issues for parabolic trough concentrating solar power (CSP) systems. This advanced receiver aims to:

- Decrease acquisition costs by simplifying structural design and manufacturing

- Achieve higher optical-field efficiency without expensive coatings

- Increase reliability by eliminating vacuum-related failures

- Operate at higher temperatures by dramatically reducing radiative losses.

\section{IMPACT}

This technology represents significant operational and cost advances in the most trusted and broadly implemented form of CSP. In addition, it offers the prospect for rapid, widespread adoption in new and retrofitted installations. By significantly exceeding the trough cost-reduction targets for receivers, this innovative system provides a viable pathway to achieving SunShot's $\$ 0.06 / \mathrm{kWh}$ goal for utility-scale CSP systems.

For more information, visit the project page at: www.solar.energy.gov/sunshot/csp_sunshotrnd_norwich.html. 